Supporting Information

\title{
Effects of Superparamagnetic Iron Nanoparticles on Electrocatalysts for the Reduction of Oxygen
}

Talha Al-Zoubi, ${ }^{\dagger}$ Wei Gao,${ }^{\dagger}$ Charles E. Schulz,, Duan Luo, ${ }^{\#}$ Angela M. DiAscro, ${ }^{\ddagger}$ Jianguo Wen,

${ }^{\#}$ Andrew A. Gewirth, ${ }^{\ddagger}$ and Hong Yang ${ }^{\dagger,+}, *$

${ }^{\dagger}$ Department of Chemical and Biomolecular Engineering, University of Illinois at UrbanaChampaign, 600 S. Mathews Avenue, Urbana, Illinois 61801, United States

" Department of Physics, Knox College, 2 East South Street Galesburg, Illinois 61401, United States

${ }^{\#}$ Center for Nanoscale Materials (CNM), Argonne National Laboratory, 9700 South Cass Avenue, Argonne, Illinois 60439, United States

$¥$ Department of Chemistry, University of Illinois at Urbana-Champaign, 505 S. Mathews Avenue, Urbana, Illinois 61801, United States

*: Corresponding author: hy66@illinois.edu 


\section{Figures}

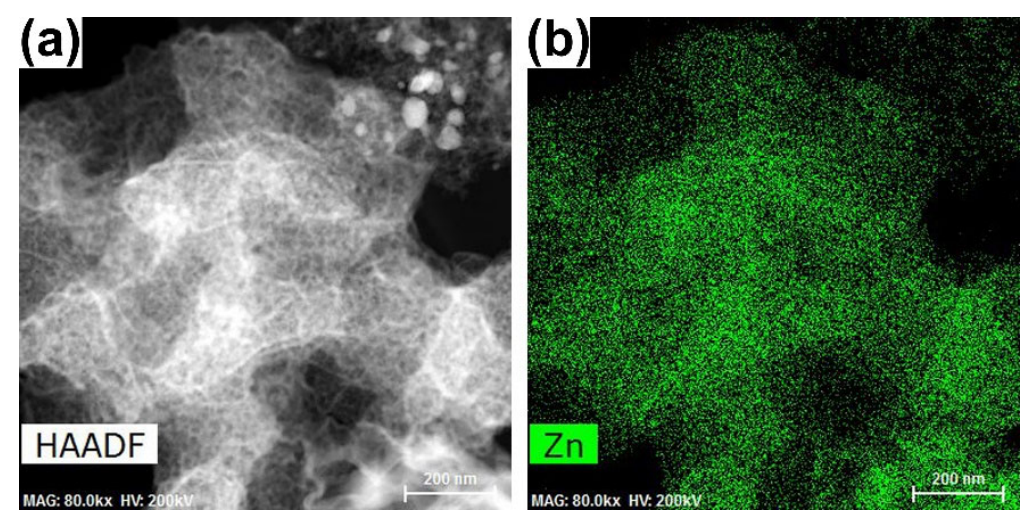

Figure S1. (a) Representative HAADF-STEM image (b) EDS map of the FeNC 750 samples showing the existence of remaining zinc after pyrolysis. 


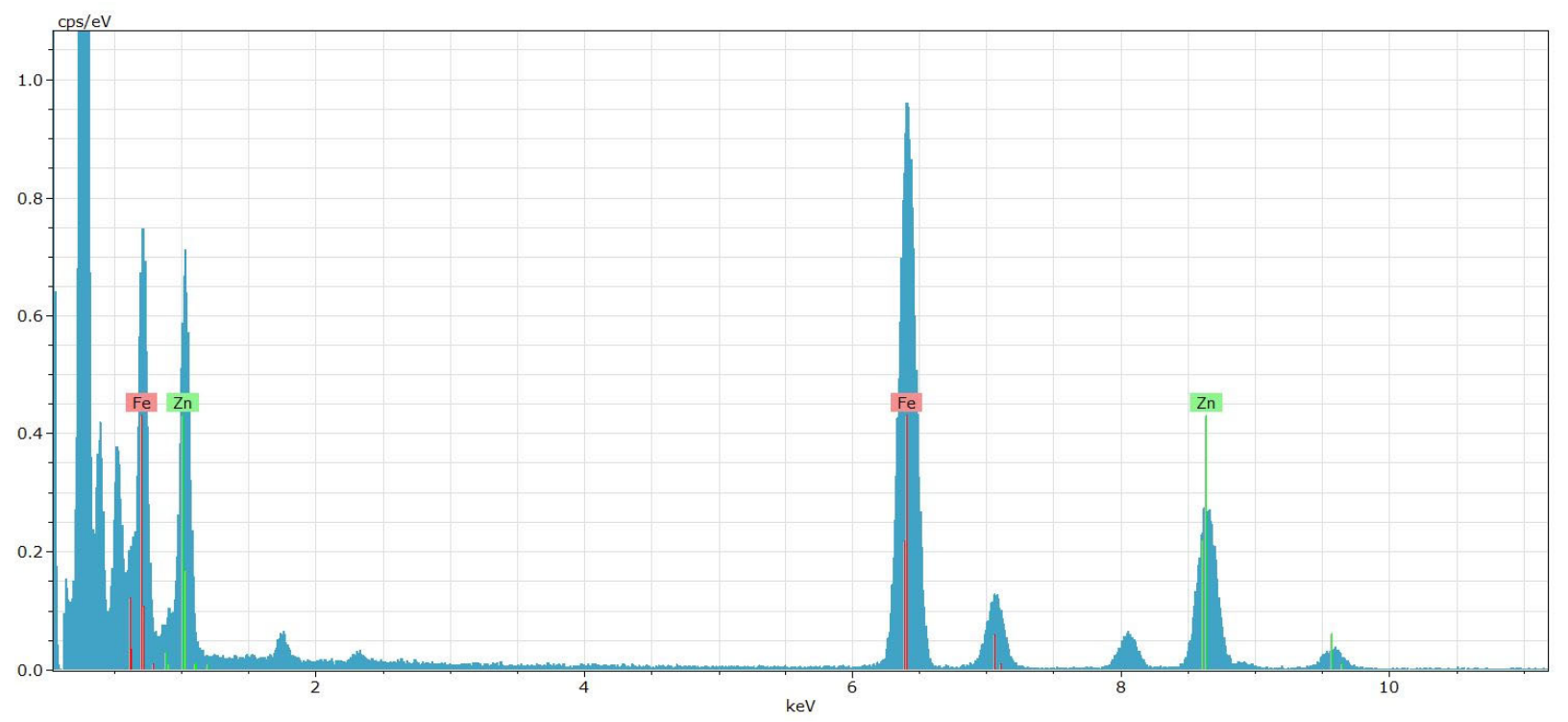

Figure S2. EDS spectrum showing the presence of $\mathrm{Zn}$ and Fe. 


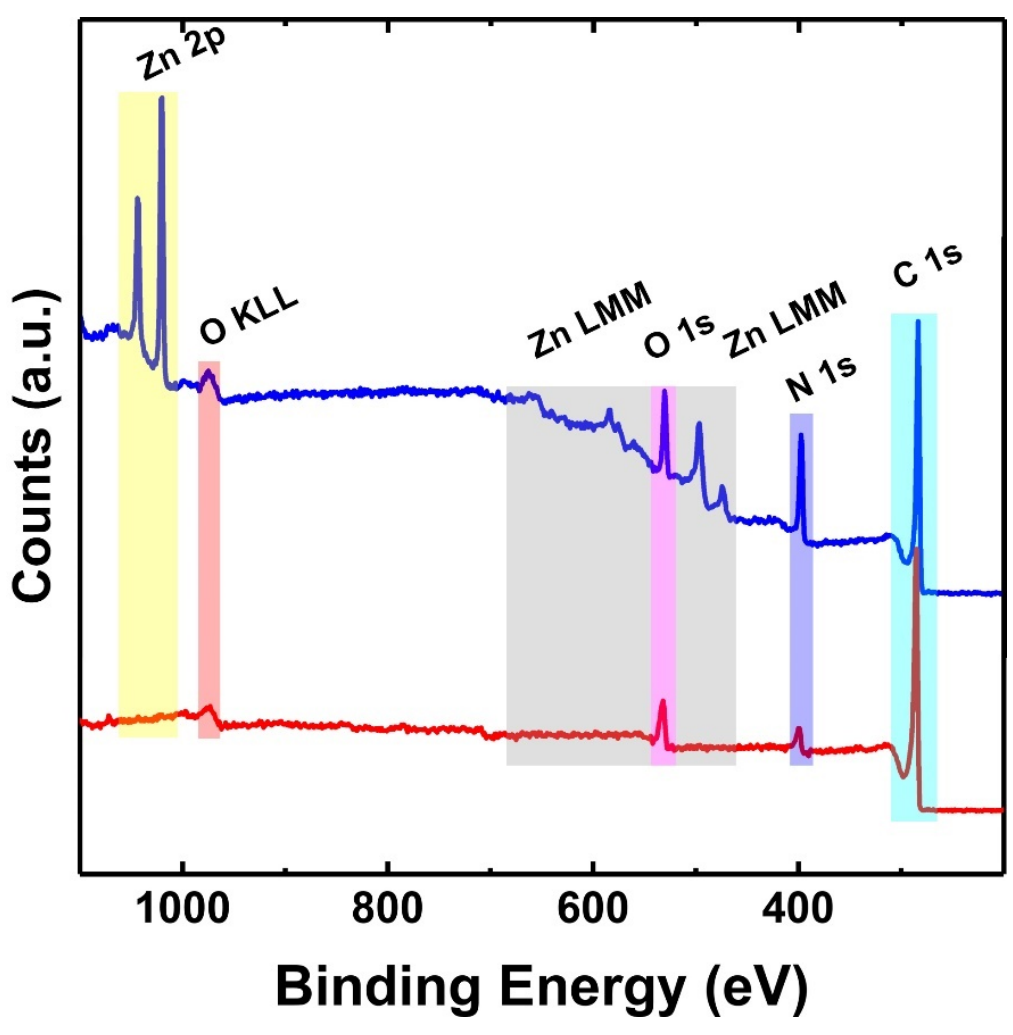

Figure S3. XPS survey scans for $\mathrm{FeNC}_{750}$ (top, blue) and $\mathrm{FeNC}_{950}$ (bottom, red) samples with regions of relevant elements being highlighted. The signals for zinc were clearly observable for the $\mathrm{FeNC}_{750}$ sample, but absence from the $\mathrm{FeNC}_{950}$ sample. 

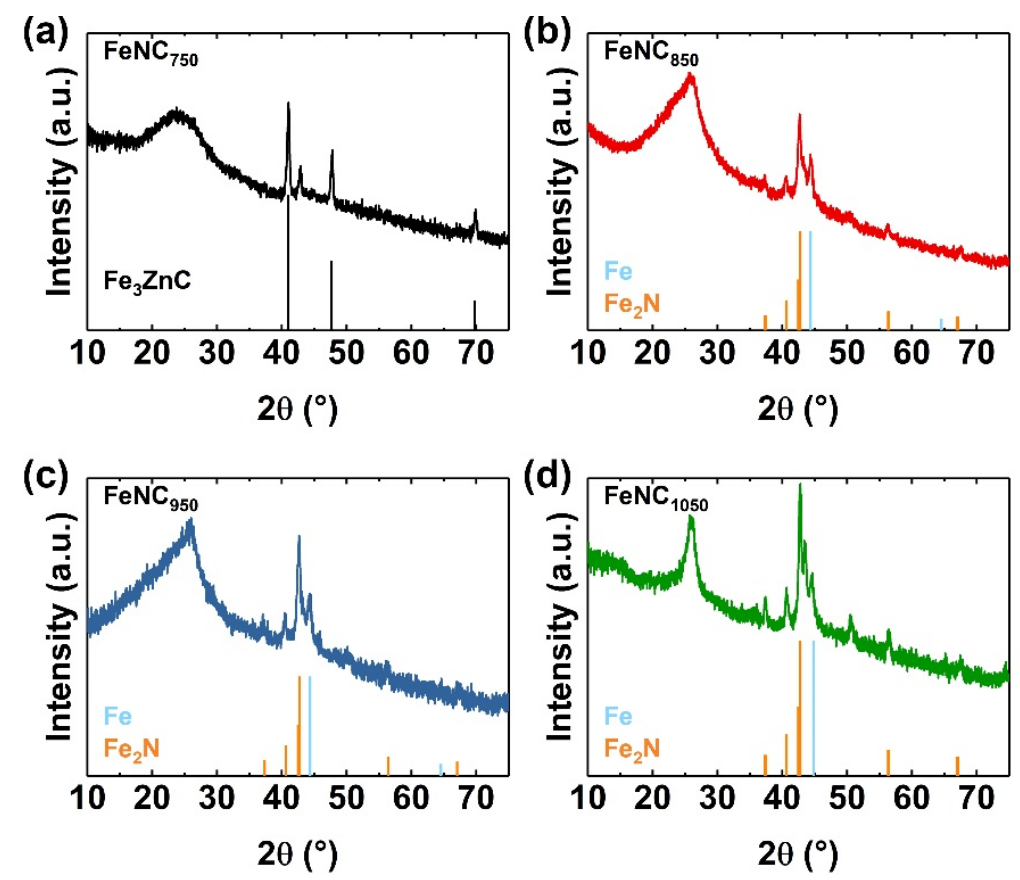

Figure S4. XRD patterns showing the formation of various Fe and $\mathrm{N}$ containing species in the as-made catalysts. 


\section{Tables}

Table S1. Iron and zinc contents in the Fe-N-C electrocatalysts determined by inductively coupled plasma mass spectrometry (ICP-MS)

\begin{tabular}{|c|c|c|}
\hline & Zn (wt. \%) & Fe (wt. \%) \\
\hline FeNC $_{\mathbf{8 5 0}}$ & 4.3 & 5.6 \\
\hline FeNC $_{950}$ & 0.18 & 5.5 \\
\hline FeNC $_{\mathbf{1 0 5 0}}$ & 0.01 & 7.2 \\
\hline
\end{tabular}

Table S2. Mössbauer spectroscopy results for the Fe-N-C electrocatalysts

\begin{tabular}{|c|c|c|c|c|c|}
\hline Sample & Component & $\begin{array}{c}\delta_{\text {iso }} \\
\left(\mathrm{mm} \mathrm{s}^{-1}\right)\end{array}$ & $\begin{array}{c}\Delta E_{Q} \\
\left(\mathrm{~mm} \mathrm{~s}^{-1}\right)\end{array}$ & $\begin{array}{l}\text { FWHM } \\
\left(\mathrm{mm} \mathrm{s}^{-1}\right)\end{array}$ & Assignment \\
\hline \multirow{2}{*}{$\mathrm{FeNC}_{850}$} & Doublet & 0.37 & 0.97 & 0.60 & $\mathrm{FeN}_{\mathrm{x}}$ \\
\hline & Singlet & -0.07 & - & 0.26 & $\alpha-\mathrm{Fe}$ \\
\hline \multirow{2}{*}{ FeNC950 } & Doublet & 0.32 & 0.89 & 0.82 & $\mathrm{FeN}_{\mathrm{x}}$ \\
\hline & Singlet & -0.1 & - & 0.35 & $\alpha-\mathrm{Fe}$ \\
\hline \multirow{2}{*}{$\mathrm{FeNC}_{1050}$} & Doublet & 0.22 & 0.96 & 0.34 & $\mathrm{FeN}_{\mathrm{x}}$ \\
\hline & Singlet & -0.07 & - & 0.35 & $\alpha-\mathrm{Fe}$ \\
\hline
\end{tabular}

